\title{
On the experimental Mixed-Mode failure of adhesively bonded metallic joints
}

\author{
G. Stamoulis ${ }^{a},{ }^{*}$, N. Carrere ${ }^{a}$, J.Y. Cognard ${ }^{a}$, P. Davies ${ }^{b}$, C. Badulescu ${ }^{a}$ \\ a Laboratoire Brestois de Mécanique et des Systèmes (EA4325), ENSTA-Bretagne, 2 rue François Verny, 29806 \\ Brest Cedex 9, France \\ ${ }^{\mathrm{b}}$ Materials \& Structures Group, IFREMER, Centre de Brest, France B.P. 70, 29280 Plouzané Cedex, France \\ *: Corresponding author: G. Stamoulis
}

\begin{abstract}
:
The use of adhesively bonded structures is widespread in various engineering fields, as they provide many advantages over other conventional types of mechanical joints. In this study, we use a crash optimized, single-component epoxy adhesive (SikaPower ${ }^{\circledR}-498$ made of a rigid epoxy matrix containing soft, tough polymer inclusions that provide additional ductility to the adhesive layer) at a constant layer thickness of $0.5 \mathrm{~mm}$ to bond metallic substrates. We investigate its fracture properties under mode I and mixed-mode I/II loadings, in order to obtain the full fracture envelope. Mode I loading has been performed using the ISO 25217 standard: the substrates were designed according to the TDCB (Tapered Double Cantilever Beam) geometry, and the fracture toughness $G_{I C}$ has been calculated by means of the ECM (Experimental Compliance Method). Mixed-Mode I/II loading has been applied using the MMB (Mixed Mode Bending) experimental fixture described in the ASTM D6671 standard. The fracture toughness $G_{C}$ has been calculated via Finite Element Analysis and mode partitioning has been determined according to the methodology described in the standard. The mixed mode fracture behavior measured using the previous two methodologies shows that the adhesive seems to follow the Benzeggagh - Kenane failure criterion (expressed in 2D).
\end{abstract}

Keywords : Fracture toughness ; Linear Elastic Fracture Mechanics (LEFM) ; Adhesive bonding ; Finite Element Analysis (FEA) ; Failure criterion 


\section{Introduction}

Adhesion technology is the most popular solution for many joining situations. It provides several advantages over other more conventional types of mechanical connections, such as: more uniform stress distribution along the bonded area, the ability to bond dissimilar materials and an improved resistance to corrosion. It is also a key option for automotive and aeronautic industries to reduce the weight of modern means of transport. This continuous use of adhesives makes it imperative to predict the durability of adhesively bonded structures. To achieve this target, most of the researchers use concepts coming from the fracture mechanics. In fracture mechanics rupture is assumed to occur when a crack in a solid medium extends over a unit area. This crack extension is related to a net decrease in the stored potential energy of the loaded system: the critical strain energy release rate or fracture toughness ( $G_{C}$, the term rate refers to the change in potential energy with the crack area). Based on the state at the end of the crack tip, 3 loading modes can be distinguished: mode I (the tensile opening mode), mode II (the in-plane shear mode) and mode III (the anti-plane shear mode).

Two substrate geometries have been widely employed in measuring the fracture toughness of the adhesive under pure mode I loading $\left(G_{I C}\right)$ : the DCB (Double Cantilever Beam) and the TDCB (Tapered Double Cantilever Beam). Their origins are found in the early work of Ripling and coworkers [1, 2]. This work led to the publication of a standard (ASTM D3433, [3]). Later on, the tests have been reviewed [4, 5] and a new standard has been published (ISO 25217, [6]). In both [3] and [6] 
standards, $G_{I C}$ is calculated using the LEFM (Linear Elastic Fracture Mechanics) principles, and in particular the Irwin - Kies equation [7]

$$
G_{C}=\frac{F^{2}}{2 b} \frac{d C}{d a}
$$

where $G_{C}$ is the fracture toughness for the case of a linear-elastic solid (it is obvious that $G_{C}=G_{I C}$ for the pure mode I loading case), $F$ is the applied force, $b$ is the specimen width and $d C / d \alpha$ denotes the rate of change of the system compliance $C$ with respect to the crack length $\alpha$. The calculation of $G_{C}$ using equation (1) depends on the proper measurement of $d C / d \alpha$. Both [3] \& [6] standards propose analytical and experimental methods to perform this measurement.

Contrary to the pure mode I loading case, measuring the fracture toughness of adhesives under pure mode II loading $\left(G_{I I C}\right)$ is a significantly more complex task, and is still not standardized. Tests have been developed mainly for fiber-reinforced polymer composites and have been implemented to study the mode II fracture of structural adhesives. The most popular of these are the ENF (End-Notched Flexure) and the ELS (End-Loaded Split) tests. Analytical expressions to determine $G_{I I C}$ of an adhesive using the ENF test are given by Alfredsson [8] and Leffler et al. [9]. Blackman et al. [10] applied the ELS test to measure the $G_{I I C}$ of an adhesive using carbon-fiber-reinforced composite adherends. In 1999, Martin and Davidson [11] presented a different version of the ENF test, the 4-point ENF test, for measuring the $G_{I I C}$ fracture toughness of laminated composites. This test has also been applied to adhesive joints. Similarly to the pure mode II load case, the fracture characterization of adhesives under pure mode III loading is also very complicated to perform. It has been very little studied by researchers mostly due to the lack of industrial interest for this failure mode. In most 
cases the mode III fracture toughness $\left(G_{I I I C}\right)$ has been considered as equal to the $G_{I I C}$ fracture toughness. Examples of test methodologies for pure mode III fracture characterization of adhesives are given in [12] (the Notched Torsion Test) and by Chai [13].

The calculation of the fracture toughness of the adhesive layer under all 3 loading modes often depends on the experimental measurement of the crack length. This is very difficult to accomplish due to the nucleation of micro-cracks in the fracture zone formed ahead of the crack tip. Some alternative methods to overcome this problem have been developed involving the experimental measurement of other quantities [14, 15]. In the 1980s, cohesive zone models have also been introduced as an alternative to predict the strength of adhesively bonded structures [16]. Using cohesive elements, the adhesive layer can be modeled as a material volume with its constitutive parameters represented by a cohesive law. Cohesive elements have often been used together with the $J$-contour integral method to calculate the fracture toughness of adhesively bonded joints. The $J$ contour integral was first introduced by Rice [17] and is the fundamental principle of Elastic-Plastic Fracture Mechanics. It is given by

$$
J=\int_{\Gamma}\left(W d y-\boldsymbol{T} \frac{\partial u}{\partial x}\right) d s
$$

where $\Gamma$ is an arbitrary counterclockwise path around the crack tip starting at the lower crack face circumscribing the crack tip and ending at the upper face, $W=\int \boldsymbol{\sigma} d \boldsymbol{\varepsilon}$ is the strain energy density with $\sigma$ and $\varepsilon$ being the stress and strain tensors respectively, $\boldsymbol{T}=\boldsymbol{\sigma n}$ is the traction vector with $\boldsymbol{n}$ being the unit vector normal to the contour $\Gamma$, and $d s$ is the length increment along the contour $\Gamma$. Expression (2) implies that the coordinate system is oriented with the $\mathrm{x}$-axis pointing to the direction of the crack 
propagation. In the case of a linear elastic material $J=G_{C}$, where $G_{C}$ is the fracture toughness calculated from the Irwin-Kies equation (1).

The objective of the present study is to propose a mixed-mode energetic failure criterion for adhesively bonded metallic substrates derived from experimental measurements. The determination of such criteria for structural adhesives is of particular industrial interest. Indeed, if the mixed-mode energetic failure criterion of the adhesive is known, the strength of the metallic joint can be predicted by equating the energy release rate to the toughness at the appropriate phase angle. Chai [13] has proposed a general form of a power law [18] mixed-mode energetic failure criterion for adhesively bonded structures, which when neglecting the mode III failure takes the form

$$
\left(\frac{G_{I}}{G_{I C}}\right)^{m}+\left(\frac{G_{I I}}{G_{I I C}}\right)^{n}=1
$$

where $G_{I}$ and $G_{I I}$ denote the mode I and mode II strain energy release rates respectively after mode partitioning and $m, n$ are material parameters to be determined. The power law criterion has been used by many researchers as a mixed-mode energetic failure criterion assuming either $\mathrm{m} \neq \mathrm{n}$ [19] or $\mathrm{m}=\mathrm{n}$ [20-23], along with different joint geometries. A meso-mechanical model to show how mixed-mode loading influences the fracture characterization of thin adhesive layers is proposed by Salomonson [24].

In the present work, we have chosen to bond metallic substrates with the crashoptimized single-component epoxy adhesive SikaPower ${ }^{\circledR}-498$ (made of a rigid epoxy matrix containing soft, tough polymer inclusions that provide additional ductility to the adhesive layer). Crash-optimized adhesives are of particular interest due to their high fracture resistance values. The SikaPower ${ }^{\circledR}-498$ adhesive has also been investigated by Marzi et al. [25] who used metallic adherends to evaluate the influence of its layer 
thickness on the fracture toughness under pure mode I and pure mode II loadings. For the case of mode I loading, we chose the TDCB substrate geometry. This has been designed according to the general directions given in the ISO 25217 [6] standard. The advantage of this geometry is that it enables the fracture toughness $G_{I C}$ to be measured without explicitly requiring the crack length measurements. The TDCB experiments have been evaluated using the Irwin-Kies equation (1) together with the Experimental Compliance Method (ECM) [6]. The mixed-mode I/II fracture behavior has been studied by means of the Mixed Mode Bending (MMB) test. This test has been standardized for composite materials (ASTM D6671 [26]). We used the experimental setup proposed in the standard, which was initially developed by Reeder and Crews [27] in 1988. It was designed to study crack growth behavior of composites under mixedmode I/II loading. However, it can be easily adapted to adhesively bonded joints (figure 5). Its particular advantage is that a range of mixed-mode I/II load cases can be studied without having to change the specimen geometry. This can be achieved simply by changing the lever arm $c$ (figure 5a). Thus, the MMB test fixture is particularly suitable to obtain the full fracture resistance envelope. It has already been used in the past to study the resistance of adhesively bonded composites [28]. To calculate the adhesive fracture toughness, we developed a Finite Element Model of the experiment using the Abaqus $^{\mathrm{TM}}$ Ver.6.10-EF1 software. Mode partitioning has been performed according to the methodology described in the ASTM D6671 [26] standard. The results from the TDCB and MMB tests can be used to obtain the full mixed-mode I/II fracture envelope of the adhesive under investigation. 


\section{Experiments and discussion}

The experiments have been carried out using an Instron tension machine (model 5566). All TDCB and MMB specimens were loaded at a constant crosshead speed of 0.5 $\mathrm{mm} / \mathrm{min}$. The TDCB substrates (figure 1a) have been fabricated out of Aluminum 2017A. Their width value has been set at $10 \mathrm{~mm}$. It was chosen as a compromise between the need to create plane strain conditions in the center of the joint width during the test, and to ensure that the adherends behave like beams rather than plates. S. Marzi et al. [25] used TDCB steel substrates of $5 \mathrm{~mm}$ of width to test the SikaPower ${ }^{\circledR}-498$ adhesive under pure mode I loading. However, the geometry of the substrates they used was based on different standards [3, 29]. The dimensions of the MMB specimens are shown in figure 2. The MMB substrates were fabricated out of a high limit of elasticity steel (Raex 450). Their dimensioning has been performed so that, after bonding, the specimen size is as close as possible to the directions given in the ASTM D6671 [26] standard for the composite test specimens geometries. In order to apply the load, load blocks were used which were glued on the substrates by means of the Araldite $420 \mathrm{~A} / \mathrm{B}$ adhesive. The mechanical properties of the raw materials used to fabricate TDCB and MMB specimens, as provided by the supplier, are given in table 1. 


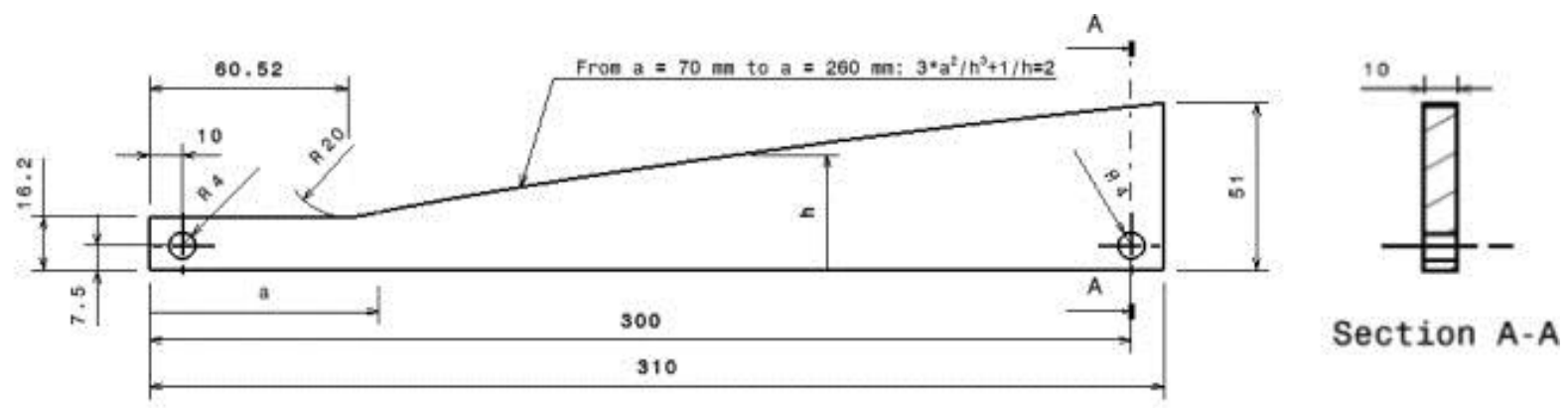

a)

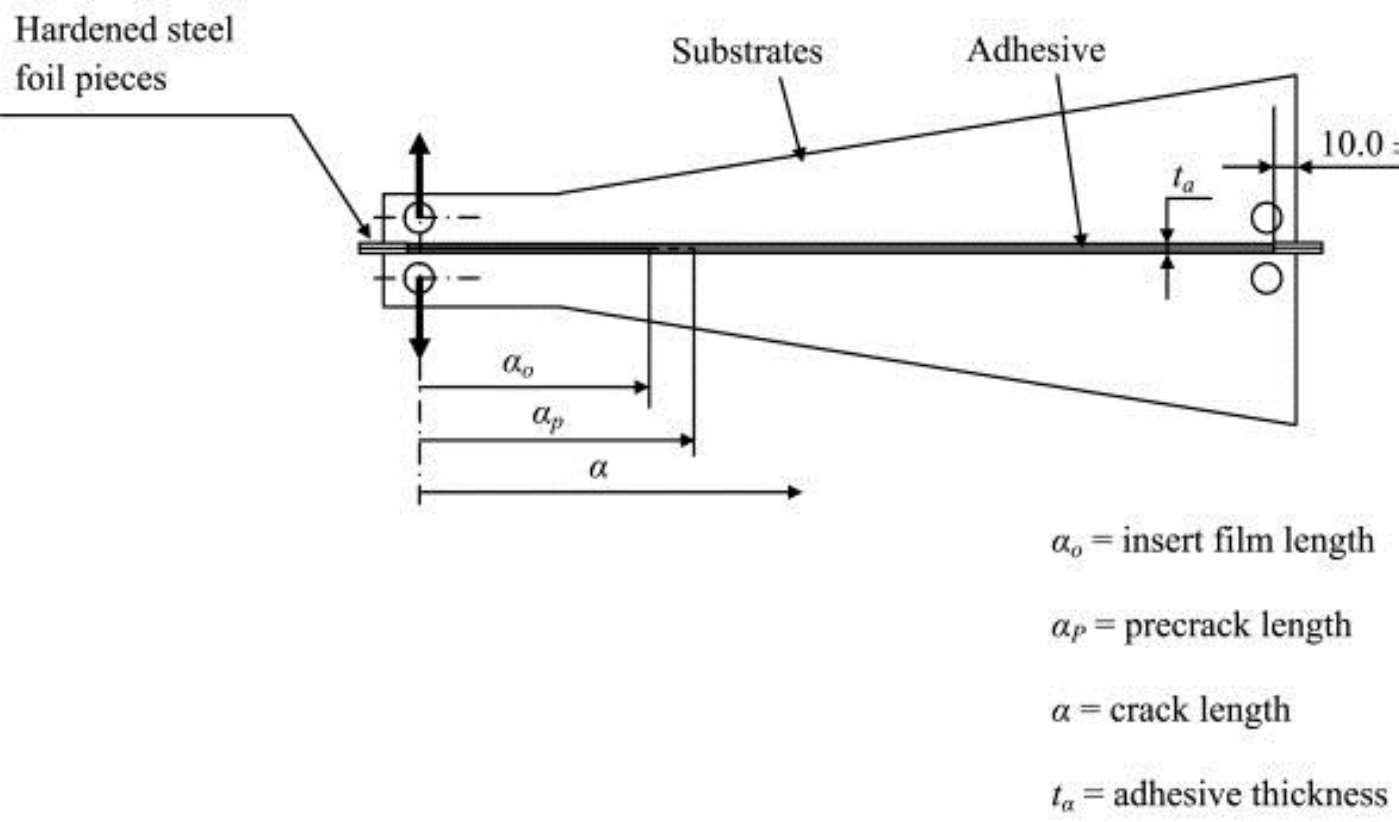

b)

Fig. 1.

(a) Dimensions (in mm) of TDCB substrates (tolerances at $\pm 0.02 \mathrm{~mm}$ ), (b) Schematization of the TDCB specimen, showing also the loading principle (dimensions in $\mathrm{mm}$ ). 


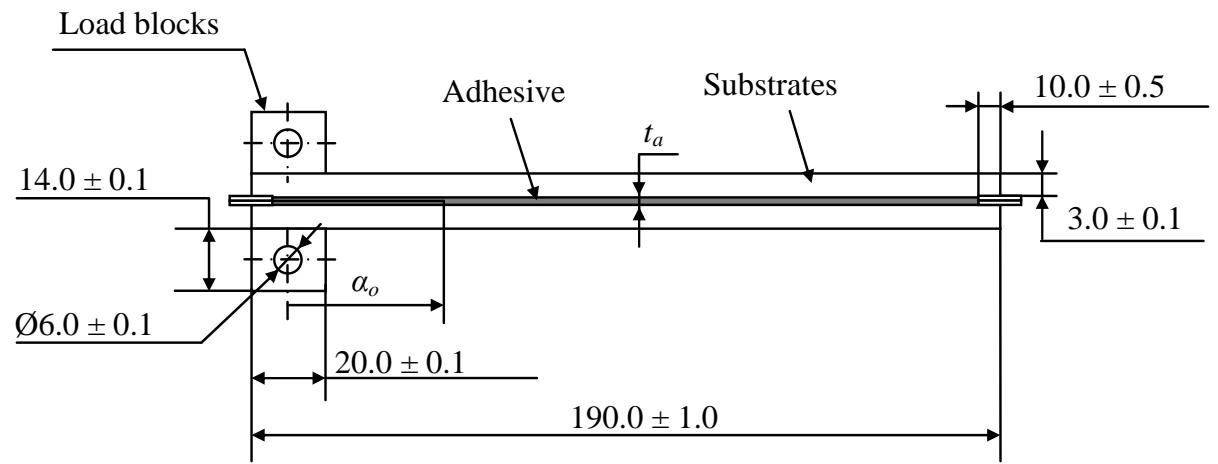

a)

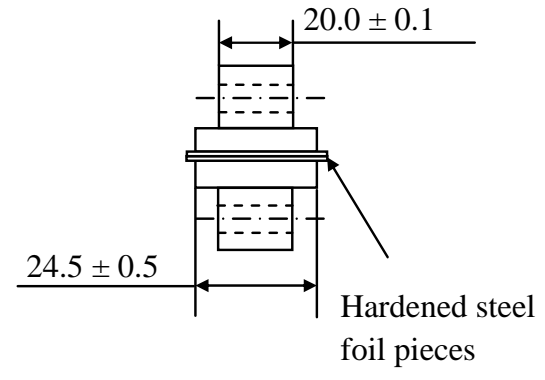

b)

Figure 2: Dimensions (in mm) of MMB specimens, a) front view, b) side view

\begin{tabular}{|l|l|l|l|l|l|}
\cline { 2 - 6 } \multicolumn{1}{c|}{} & $\begin{array}{l}\text { Modulus of } \\
\text { Elasticity (E, GPa) }\end{array}$ & $\begin{array}{l}\text { Shear Modulus } \\
(\mathbf{G}, \mathbf{M P a})\end{array}$ & $\begin{array}{l}\text { Poisson } \\
\text { coefficient (v) }\end{array}$ & $\begin{array}{l}\text { Yield Stress } \\
(\mathbf{M P a})\end{array}$ & $\begin{array}{l}\text { Ultimate } \\
\text { stress (MPa) }\end{array}$ \\
\hline Aluminum 2017A & 72.5 & 27 & 0.33 & 280 & 420 \\
\hline Raex 450 & 210 & 78.5 & 0.33 & 1200 & 1450 \\
\hline
\end{tabular}

Table 1: Mechanical properties of the raw materials of the TDCB and MMB substrates

The adhesive layer thickness has been kept constant for all TDCB and MMB specimens at $0.50 \pm 0.05 \mathrm{~mm}\left(t_{a}\right.$, figures $\left.1 \mathrm{~b}, 2 \mathrm{a}\right)$. A pair of $0.25 \mathrm{~mm}$ thick hardened steel foil pieces has been used for this purpose (figures $1 \mathrm{~b} \& 2$ ). The exact point of their placement was at $10 \pm 0.5 \mathrm{~mm}$ from each substrate extremity. The substrate surfaces to be joined were first ground with a 180 grit Silicon Carbide (SiC) paper and then cleaned by means of 99\% pure acetone. Just before bonding, these surfaces were cleaned by means of oilfree compressed air. The initial crack length $\left(\alpha_{o}\right.$, figures $\left.1 \mathrm{~b} \& 2 \mathrm{a}\right)$ has been created via 
an aluminum foil having a thickness of $0.011 \mathrm{~mm}$. This aluminum foil was coated on both sides with Silicone Paste 70428 (used for lubrication in food industry) before its placement inside the adhesive layer. This procedure is necessary to prevent bonding of the aluminum foil to the adhesive bulk material. The SikaPower ${ }^{\circledR}-498$ adhesive has been stored at a temperature of $0{ }^{\circ} \mathrm{C}$ before use. Just before its application, it was taken out of the refrigerator and left to warm at ambient temperature for 1 hour. After this step, it was placed in a $60{ }^{\circ} \mathrm{C}$ pre-heated furnace and was left to heat for 30 minutes. Then, it was taken out, placed in an adhesive gun and applied onto the surfaces to be bonded by means of a wood spatula as quickly as possible, so as not to allow it to cool significantly. After application of the adhesive, the coated aluminum foil was placed at the specific distance $\alpha_{o}$ from the loading line (figures $1 \mathrm{~b} \& 2 \mathrm{a}$ ). The exact point of placement of the aluminum foil has been marked on both sides of all TDCB and MMB substrates by means of gauge calipers before application of the adhesive. Excessive care has been taken to keep the foil as close as possible to the middle of the adhesive layer. After placing the aluminum foil, the two substrate surfaces to be bonded were brought face to face and clamped together. Uniform pressure has been applied throughout the whole length of the TDCB and MMB specimens during this step so as to obtain a uniform layer thickness $t_{a}$. The clamped specimens were entered in a $180{ }^{\circ} \mathrm{C}$ pre-heated furnace and left to cure for 1 hour, following the instructions provided by the supplier of the adhesive. After curing, they were removed from the furnace and left to cool at ambient temperature. When cooled, the clamps were removed and the adhesive excess on both sides of the TDCB and MMB specimens was removed by grinding with a 180 grit SiC paper. The finishing was done with a 1200 grit SiC paper. 


\subsection{TDCB experiments}

In order to properly measure the fracture toughness $\mathrm{G}_{\mathrm{IC}}$, a machine stiffness correction has been performed to all experimental curves issued from the TDCB tests. A rectangular piece made of tool steel and having sufficiently large dimensions has been used for this purpose: $52 \mathrm{~mm}$ (length) x $48 \mathrm{~mm}$ (height) x $12 \mathrm{~mm}$ (width). Two holes of $\varnothing 8 \mathrm{~mm}$ were drilled in this specimen to allow for the loading pins to be inserted. The piece was loaded at $0.5 \mathrm{~mm} / \mathrm{min}$ (the crosshead speed used to perform the TDCB experiments) until a maximum force of $2000 \mathrm{~N}$, and then unloaded. The procedure was repeated several times and no significant deformation of the piece, the loading pins or the machine grips has been observed. Thus, the mean displacement curve issued from this test has been used to correct the displacement values measured during the TDCB experiments before proceeding with the analysis.

For the calculation of $d C / d \alpha$ (equation (1)) a series of 5 tests has been performed using 5 different lengths of initial film inserts ( $a_{o}$, figure 1b): 70, 80, 90, $100 \& 110 \pm 1 \mathrm{~mm}$. The specimens were loaded until crack movement from the insert was detected on their edge. After observation of crack movement the specimens were unloaded, and the distance between the load-line and the crack tip (which corresponds to the crack length $\alpha$, figure 1b) was measured with gauge calipers. The displacement and force values at the moment of propagation were recorded in order to calculate the TDCB system compliance $C$. The evolution of $C$ with respect to the crack length $\alpha$ produced a linear 
graph. After performing a least squares fit of the results it was found: $d C / d \alpha=2.83 \mathrm{E}-05$ $\mathrm{N}^{-1}$.

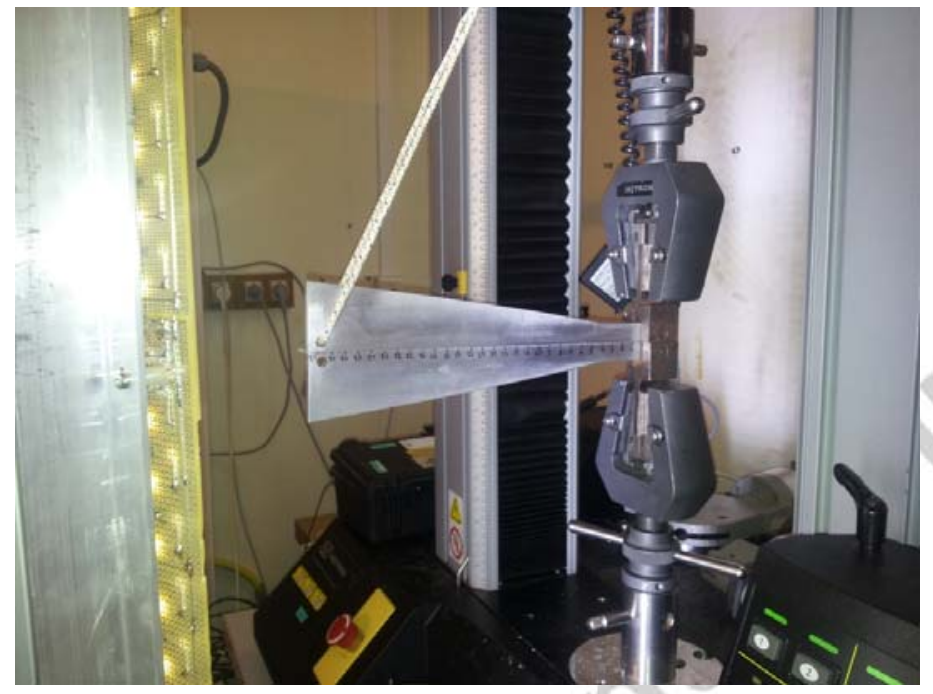

(a)

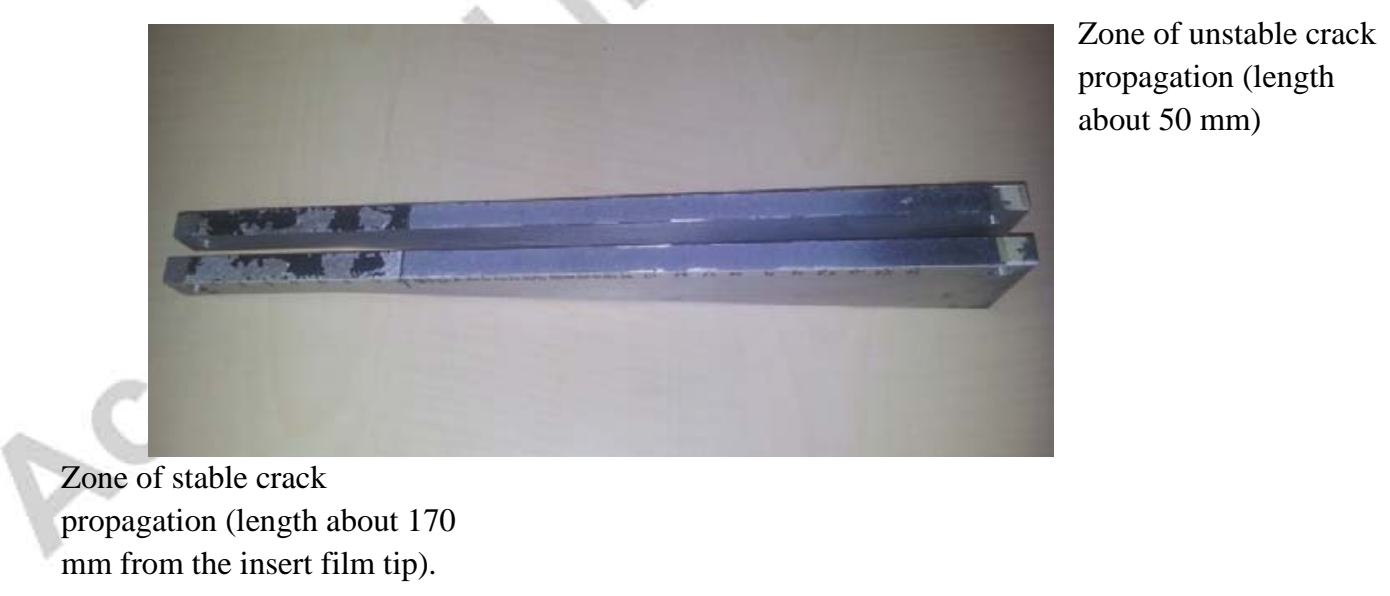

(b)

Figure 3: a) Specimen mounted on the test machine, b) example of the failure type obtained from the TDCB specimens. 
The TDCB tests have been performed on 5 specimens. Figure 3a shows the specimen mounting on the machine. The specimen was suspended with a string so as to keep it always orthogonal to the direction of the applied load. The initial film length measured from the load-line for all 5 tested pieces was kept constant at $70 \pm 1 \mathrm{~mm}$ ( $a_{o}$, figure $1 \mathrm{~b}$ ). The specimens were loaded at a constant crosshead speed of $0.5 \mathrm{~mm} / \mathrm{min}$ until total rupture. Cohesive failure has been observed in all of the TDCB specimens (figure 3b). The experimental curves obtained after performing the TDCB tests are given in figure 4 . The curves are labeled in such a way that the notation TDCB is followed by the specimen number (for example TDCB-1 corresponds to specimen number 1). As it can be concluded when examining the results, crack propagation was stable until rupture. This can be noted from the fact that the force in the force-displacement curves reaches a plateau value $\left(F_{p l}\right)$ in all experiments and no significant drop from this value has been measured afterwards. In fact, crack propagation was stable until about $170 \mathrm{~mm}$ from the tip of the insert film and then unstable until rupture (that is for the last $50 \mathrm{~mm}$ of the length of the adhesive layer, see figure $3 b$ ). This phenomenon can also be noted from the color change of the adhesive observed after rupture, which is light grey in the area of stable crack propagation and dark grey as soon as crack propagation becomes unstable. The plateau force $F_{p l}$ has been used to calculate the fracture toughness $G_{I C}$. The mean value of the measured $G_{I C}$ was of the order of $3 \mathrm{~N} / \mathrm{mm}$. All relevant results concerning the TDCB experiments are given in table 2. 


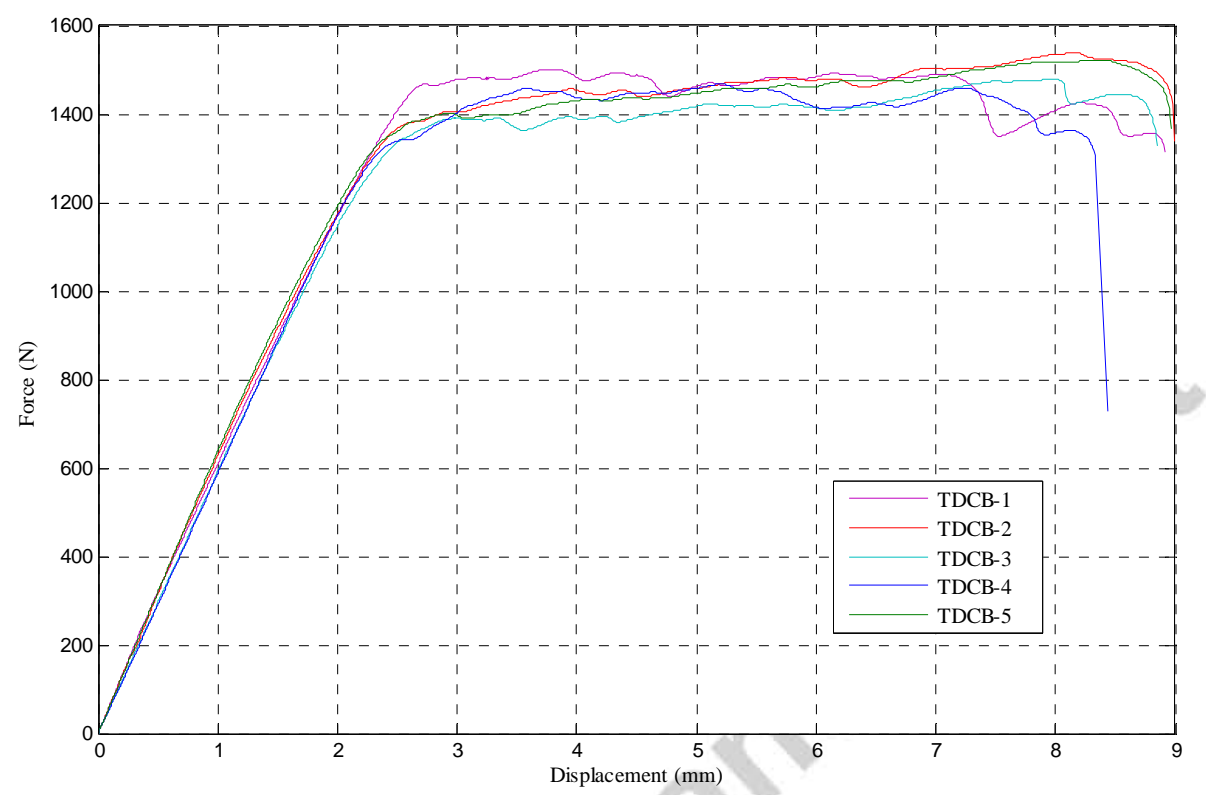

Figure 4: TDCB test experimental curves

\begin{tabular}{|c|c|c|}
\hline $\begin{array}{c}\text { Specimen number } \\
\text { TDCB-1 }\end{array}$ & $\mathbf{F}_{\mathbf{p l}} \mathbf{( N )}$ & $\mathbf{G}_{\mathbf{I C}} \mathbf{( N / \mathbf { m m } )}$ \\
\hline TDCB-2 & 1482.1 & 3.11 \\
\hline TDCB-3 & 1456.2 & 3.00 \\
\hline TDCB-4 & 1390.9 & 2.74 \\
\hline TDCB-5 & 1457.4 & 3.01 \\
\hline Statistics & 1400.6 & 2.78 \\
\hline
\end{tabular}

Table 2: Fracture toughness $G_{I C}$ results (the statistics concern the mean value \pm 2 times the standard deviation). 


\subsection{MMB experiments}

The MMB experiments have been performed with the experimental setup as shown in figure 5b. Two CCD cameras (SONY XCD SX900, black \& white, resolution $1280 \mathrm{x}$ 960 pixels), mounted with macro objective lens allowing for a 10x magnification, have been used to film the tests (figure 5b). Both cameras were synchronized with the test machine in such a way that the force value is recorded when an image is taken. Camera 1 (figure 5b) has been used to measure the crosshead displacement and thus make the necessary stiffness corrections to the experimentally obtained curves. In particular, the first and last captured images were used to calculate the total vertical displacement of the crosshead of the machine (bearing B1, figure 5b, point A, figure 6). The linear fit between the start and end points of the crosshead displacement was used to generate the intermediate points. Camera 2 (figure $5 b$ ) has been used to find the onset of crack growth and was always focused at the end of the film insert. Both cameras have been calibrated by means of millimetric paper and their acquisition frequency was $2 \mathrm{~Hz}$. 

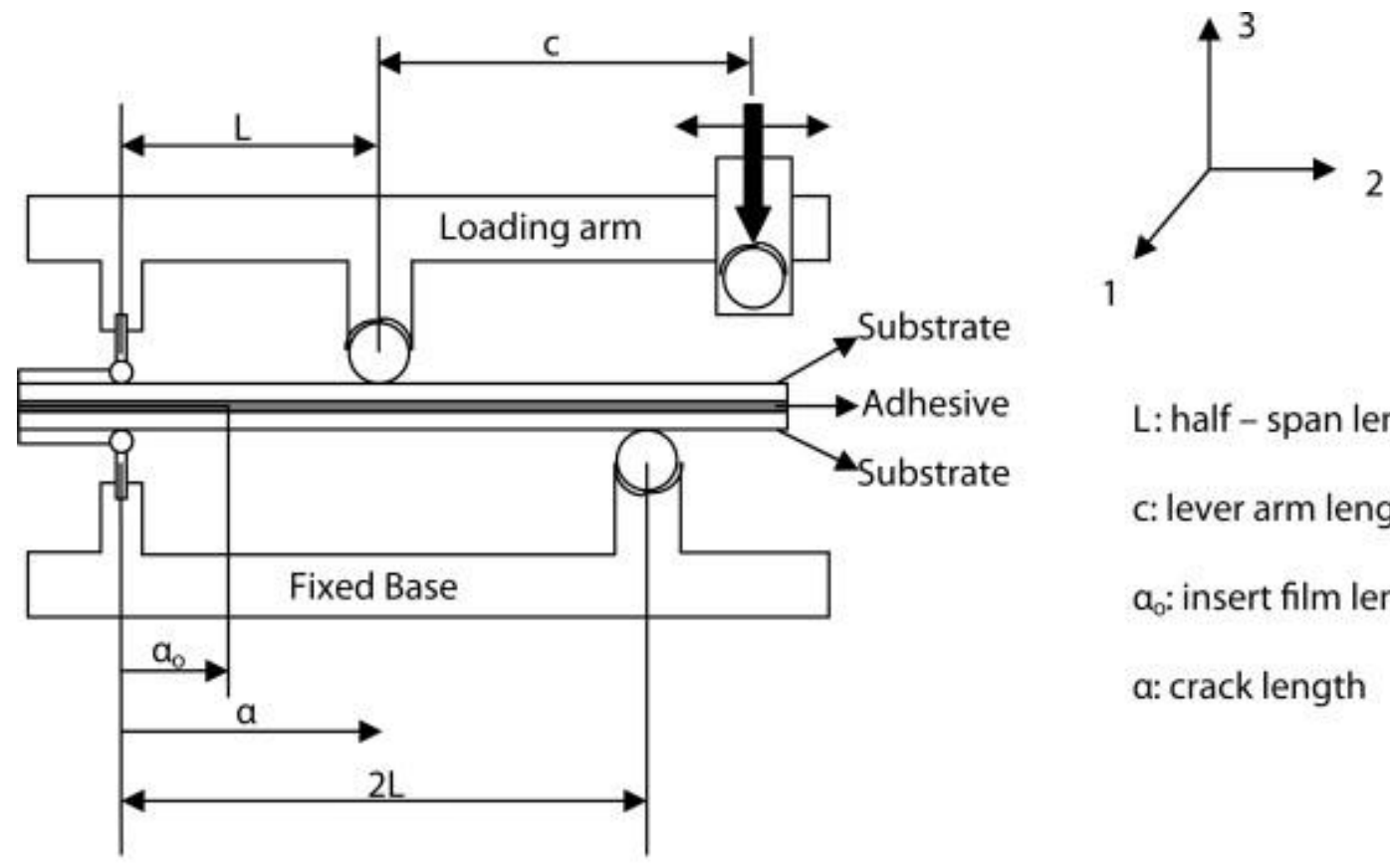
L: half - span length
c: lever arm length
$a_{0}$ : insert film length
a: crack length

(a)

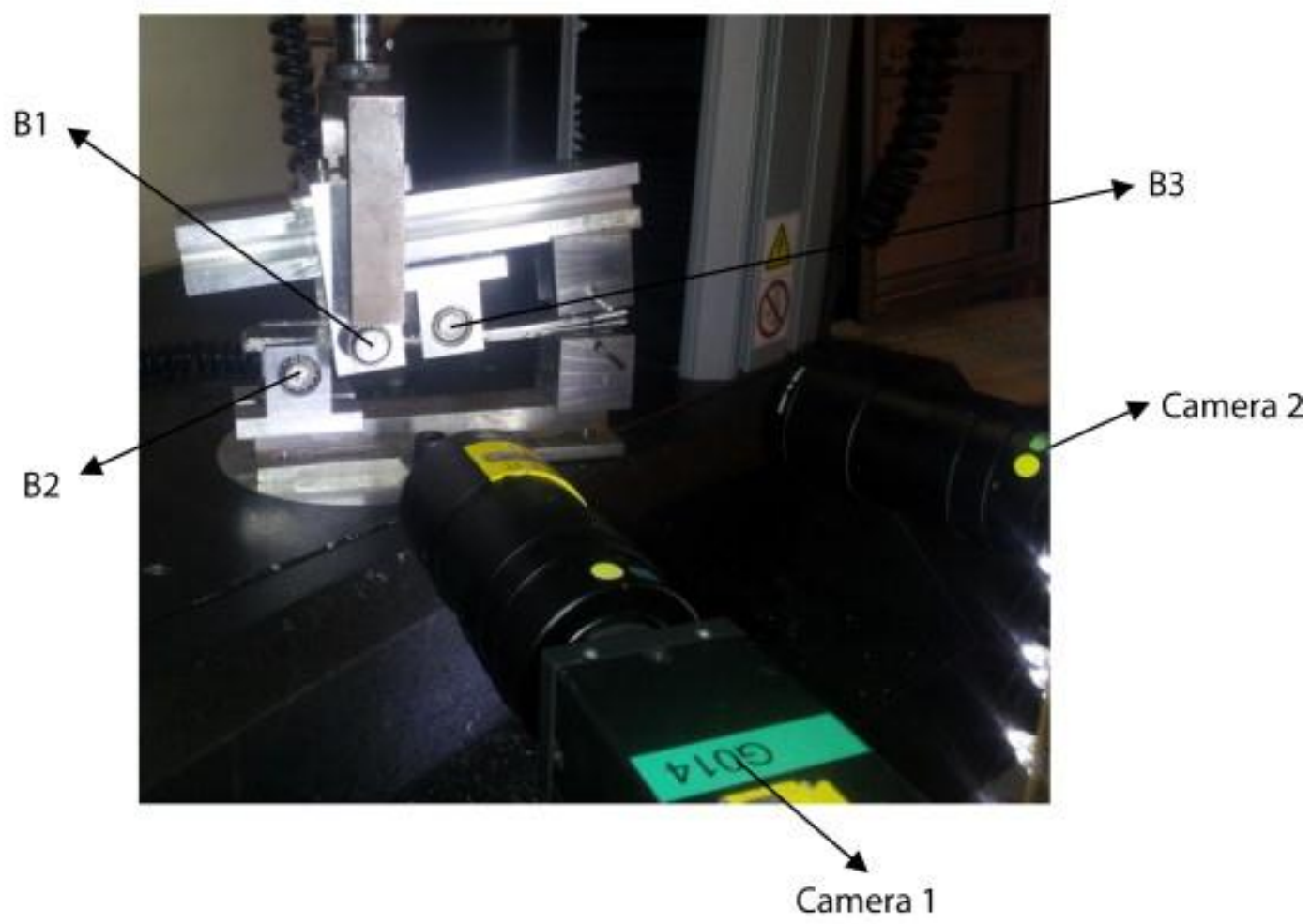

(b)

Fig. 5. MMB apparatus adapted to adhesively bonded joints: (a) fixture diagram showing the loading principle, (b) photo of the experimental setup for MMB measurements. 
Figure 5: MMB apparatus adapted to adhesively bonded joints: a) fixture diagram showing the loading principle, b) photo of the experimental setup for MMB measurements

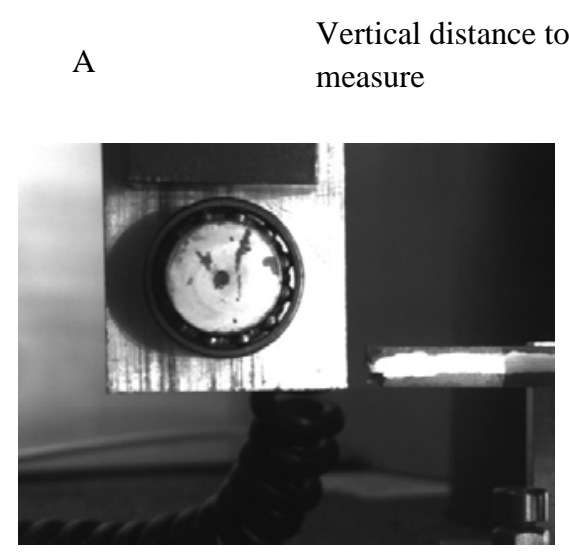

(a)

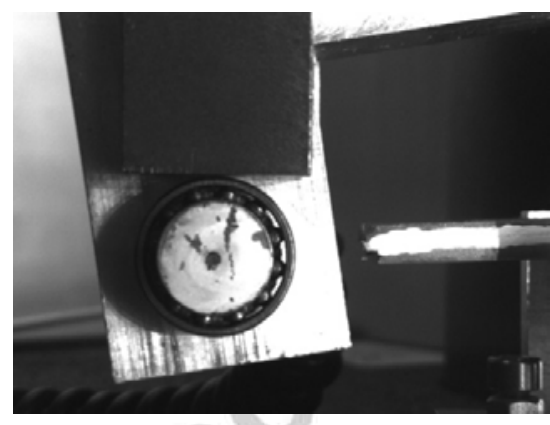

(b)

Figure 6: Stiffness correction method, a) start of experiment, b) end of experiment

According to the methodology described in the ASTM standard [26], the lever arm $c$ (figure 5a) can be calculated for the desired mode mixity using the following relations

$$
\begin{gathered}
c=\left(0.167+0.000137 \tilde{\alpha}^{2}-0.108 \sqrt{\ln (\tilde{\alpha})}\left(\frac{G_{I I}}{G_{C}}\right)^{4}+\frac{-1400+0.725 \widetilde{\alpha}^{2}-141 \ln (\widetilde{\alpha})-302 \ln \left(\frac{G_{I I}}{G_{C}}\right)}{219-5000\left(\frac{G_{I I}}{G_{C}}\right)+55 \ln (\widetilde{\alpha})}\right) L \\
\check{\alpha}=\frac{\alpha}{h \chi}, \Gamma=1.18 \frac{\sqrt{E_{11} E_{22}}}{G_{13}} \text { and } \chi=\sqrt{\frac{E_{11}}{G_{13}}\left(3-2\left(\frac{\Gamma}{\Gamma+1}\right)^{2}\right)}(4.2)
\end{gathered}
$$

where $\tilde{\alpha}$ is the non-dimensional crack length value, $h$ is the specimen half thickness, $\chi$ is the crack length correction, $\Gamma$ is the transverse modulus correction parameter, $E_{11}$ and $E_{22}$ are the longitudinal and transverse modulus respectively, $G_{13}$ is the shear out of plane modulus and $G_{I I} / G_{C}$ denotes the desired mode mixity. The directions 1,2 and 3 
are given in figure 5. Since the hardened steel (Raex 450, table 1) is much stiffer than the adhesive and since the thickness of the substrates $(3.0 \pm 0.1 \mathrm{~mm}$, figure $2 \mathrm{a})$ is much higher than the half thickness of the adhesive $(0.50 / 2=0.25 \mathrm{~mm})$, it can be assumed that the adhesive layer has a negligible effect on the overall compliance of the joint. Thus, the Raex 450 material parameters as given in table 1 can be used to calculate the lever arm $c$ for the desired mode mixity. Assuming this material is homogenous and isotropic: $E_{11}=E_{22}=210.0 \mathrm{GPa}$ and $G_{13}=78.5 \mathrm{GPa}$. As far as the half thickness $h$ is concerned, the half thickness of the specimen will be used, that is: $h=3.25 \mathrm{~mm}$.

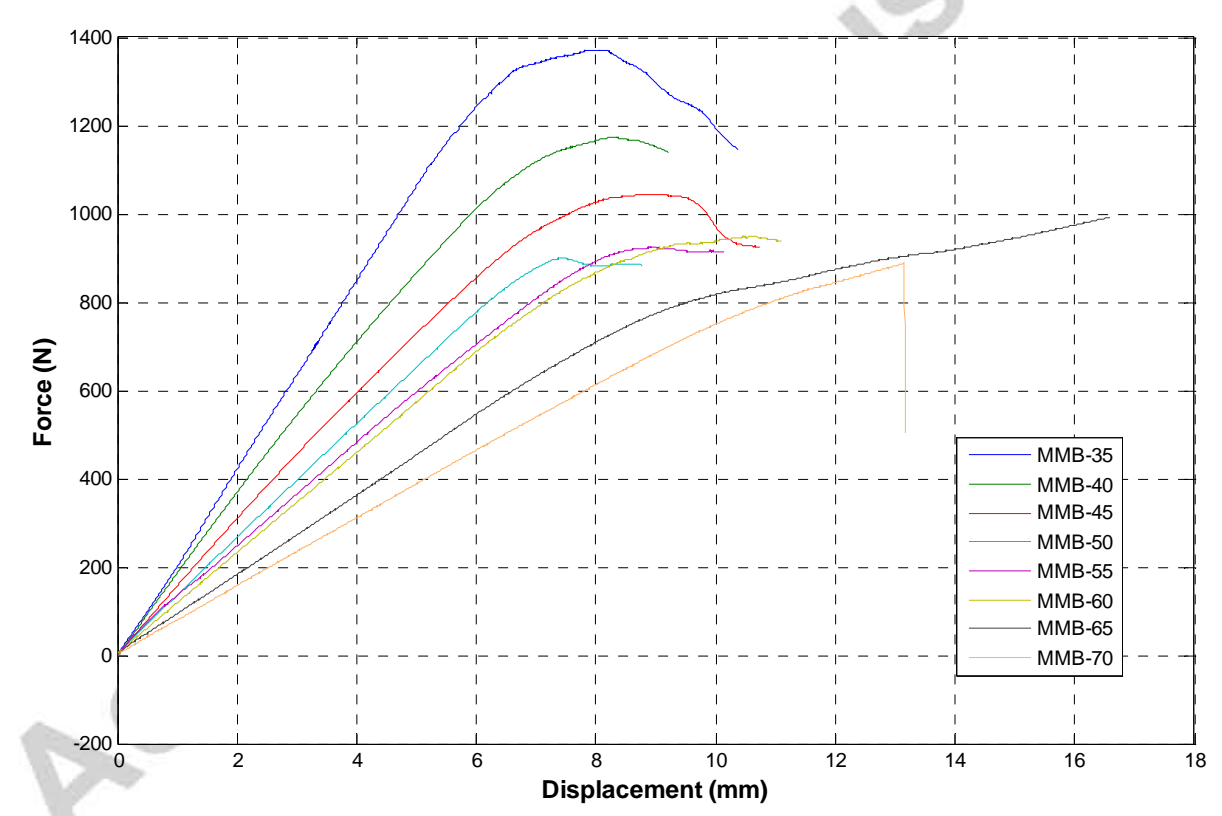

Figure 7: Results from the first evaluation of the MMB tests

Before proceeding, a first evaluation was performed in order to find the most appropriate insert film length $\alpha_{o}$ (figure 2a) for the SikaPower ${ }^{\circledR}-498$ adhesive tested in 
this study. Thus, a first series of tests has been performed varying $\alpha_{o}$ from $35 \pm 1 \mathrm{~mm}$ to $70 \pm 1 \mathrm{~mm}$ with an increment of $5 \mathrm{~mm}$. One specimen per film insert length has been used for the needs of this first evaluation. The lever arm $c$ of the MMB apparatus has been set at $64.2 \mathrm{~mm}$ and left constant. This value of $c$ corresponds to: $2 L=150 \mathrm{~mm}$, $G_{I I} / G_{C}=0.5$ and $\alpha_{o}=35 \mathrm{~mm}$. The results are shown in figure 7 . The curves in the graph are labeled in such a way that the number next to the notation MMB corresponds to the initial film length (for example MMB-35 corresponds to the specimen where $\alpha_{o}=35$ $\mathrm{mm})$. Two main observations can be made for the results in figure 7:

- As the value of $\alpha_{o}$ increases, the initial slope of the curve decreases. This is logical because the increase in the insert film length means that a higher displacement of the crosshead of the machine is required to reach the same force value with the one at lower insert film lengths.

- At low $\alpha_{o}$ lengths (35, 40 and $45 \mathrm{~mm}$ ) the force reaches a peak value and then starts to decrease as the displacement of the crosshead of the machine increases. At higher insert film lengths (50, 55 and $60 \mathrm{~mm}$ ) the force reaches the peak value without decreasing significantly afterwards. For the 2 highest $\alpha_{o}$ values (65 and $70 \mathrm{~mm}$ ) no peak value of the force has been reached before the end of the test. The tendency observed at low $\alpha_{o}$ lengths is classical for the MMB test and the decrease of the force value observed after the peak denotes the change (decrease) in the mode mixity as the crack continues to propagate. In addition, it must be noted that the validity of the equations (4) ceases at very high crack length values. These phenomena are also discussed in the relevant ASTM standard [26]. 
Based on these observations, it has been decided to continue with the lowest $\alpha_{o}$ value (that is $\alpha_{o}=35 \pm 1 \mathrm{~mm}$ ). The MMB apparatus has been configured for 4 mode mixity $G_{I I} / G_{C}$ values according to the results given for the lever arm $c$ from equations (4). The details of the configuration of the MMB apparatus are given in table 3. For each mode mixity value 3 specimens were tested. Figure 8 shows the results of the MMB tests. The notation used to identify the curves is: MMB followed by the mode mixity in percentage terms and ending with the serial number of the experiment (for example MMB20-1 corresponds to the first test performed at $\left.G_{I I} / G_{C}=0.2\right)$. The results show no significant differences between the experimental curves registered as far as the initial slope is concerned. This indicates the good repeatability of $\alpha_{0}$ in all of the specimens tested. Some differences are observed at the peak force value to either the force value itself or the displacement at peak force.

\begin{tabular}{|l|l|l|l|l|}
\hline $\boldsymbol{G}_{\boldsymbol{I I}} / \mathbf{G}$ & 0.2 & 0.4 & 0.6 & 0.8 \\
\hline $\mathbf{2 L} \mathbf{( m m )}$ & 130 & 150 & 150 & 150 \\
\hline $\boldsymbol{b}(\mathbf{m m})$ & 24.5 & 24.5 & 24.5 & 24.5 \\
\hline $\boldsymbol{a}_{\mathbf{o}}(\mathbf{m m})$ & 35 & 35 & 35 & 35 \\
\hline $\boldsymbol{c}(\mathbf{m m})$ & 129.6 & 76.7 & 55.5 & 42.1 \\
\hline
\end{tabular}

Table 3: Lever arm $c$ values and MMB configuration corresponding to the four different mode mixities 


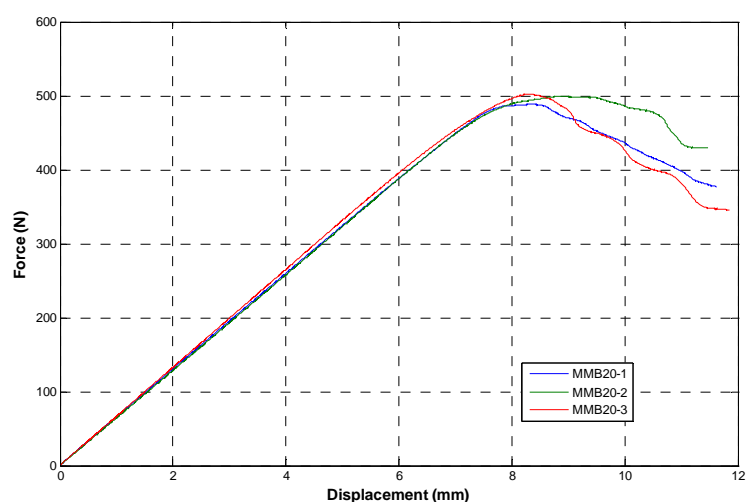

(a)

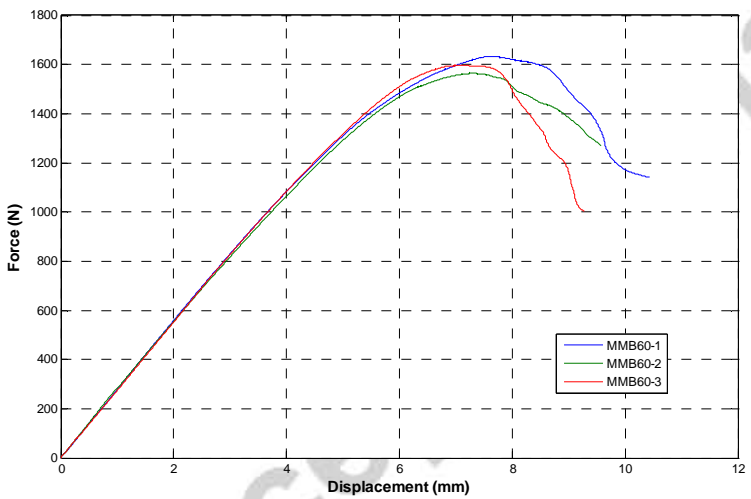

(c)

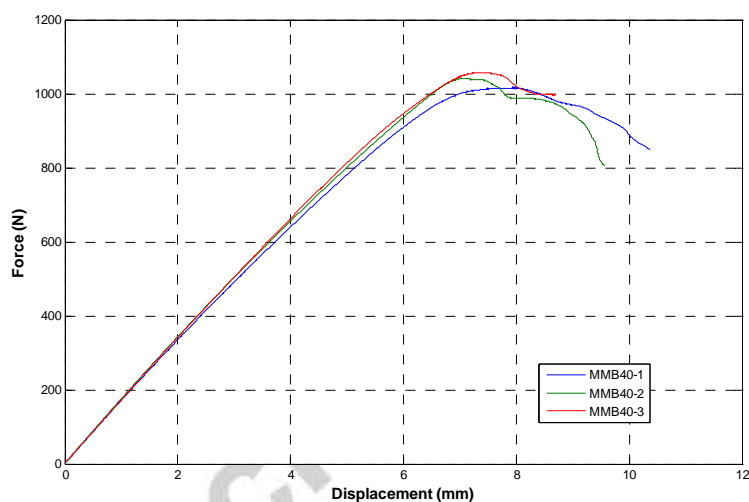

(b)

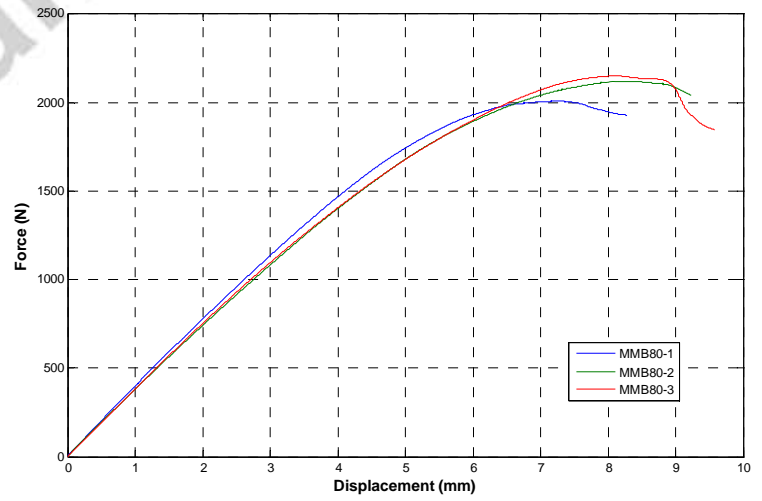

(d)

Figure 8: MMB force-displacement plots, a) $G_{I I} / G_{C}=0.2$, b) $G_{I I} / G_{C}=0.4$, c) $G_{I I} / G_{C}=$

$$
0.6 \text {, d) } G_{I I} / G_{C}=0.8
$$



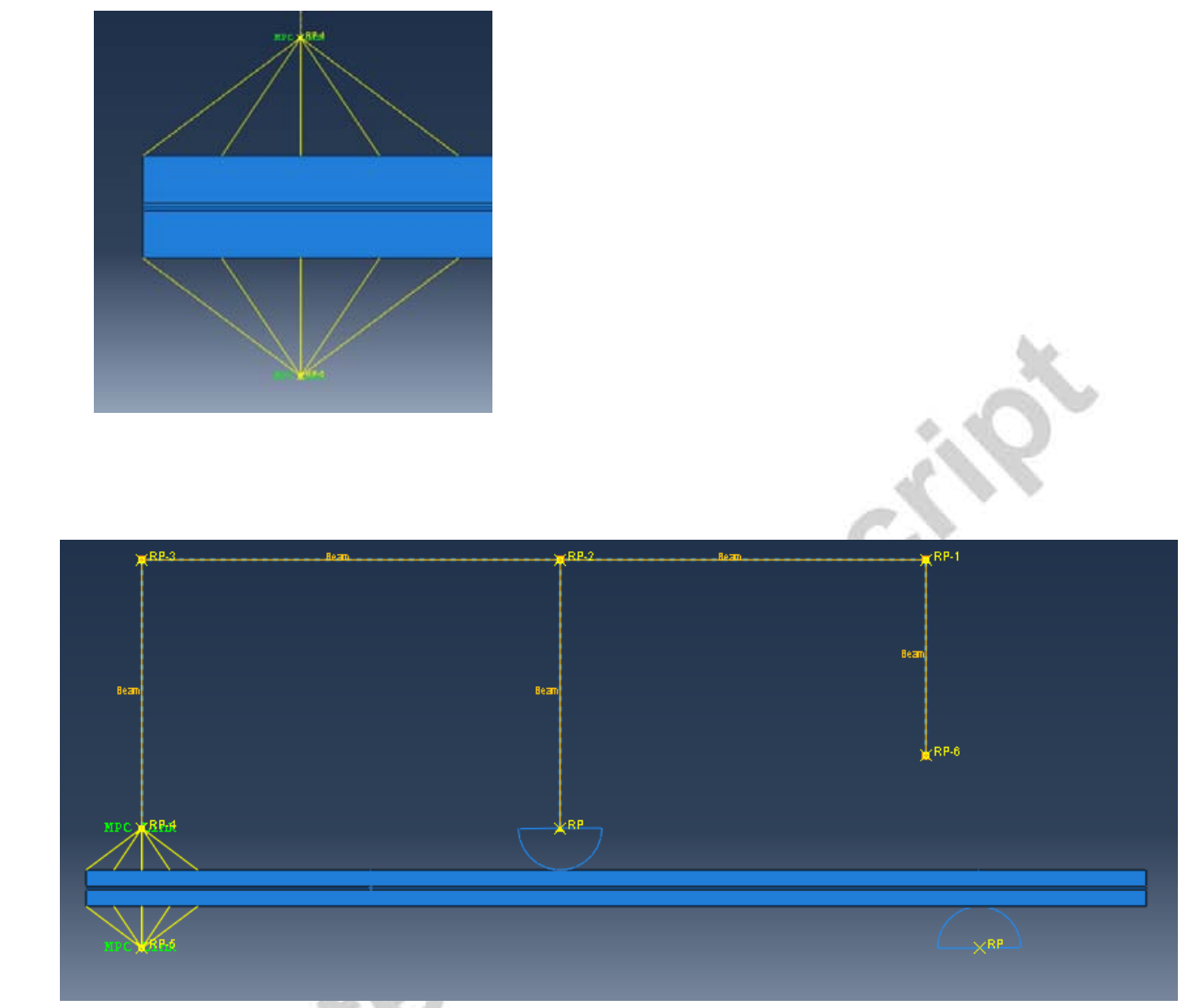

$\varnothing 0.4 \mathrm{~mm}$

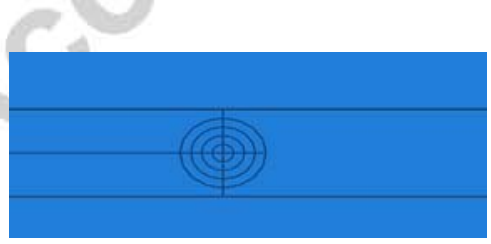

$3.0 \mathrm{~mm}$

$0.5 \mathrm{~mm}$

$3.0 \mathrm{~mm}$

Crack length

Contour design around the crack tip to calculate the J-integral

Figure 9: Finite element modeling of the MMB experiment in Abaqus ${ }^{\mathrm{TM}}$ 
In order to calculate $G_{I I}$ and $G_{I}, G_{C}$ needs to be calculated first. For this reason, a 2D finite element model of the experiment in Abaqus ${ }^{\mathrm{TM}}$ Ver.6.10-EF1 software has been developed. A general overview of the model is given in figure 9. The lever arm $c$ is represented by $\mathrm{DB}$ and the half span length $L$ by FD (see also figure $5 \mathrm{a}$ ). The load is applied at point A. The loading arm (figure 9a) is simulated by connectors of type beam of infinite rigidity between points A-B, C-D, E-F, B-D and D-F. The surfaces IMNJ and KOPL represent the upper and lower substrates. The 2 bearings B2 and B3 (figure 5b) are represented by analytical rigid surfaces in the form of circular arcs of $179^{\circ}$ (points $\mathrm{C}$ and $\mathrm{H}$, figure 9). A frictionless contact between these 2 analytical rigid surfaces and the outer surfaces of the substrates was defined. The points E and G on figure 9 represent the centers of the holes of the load blocs (see also figure 2). These 2 points are joined with a part of the outer surface of the substrates with a Multiple Point Constraint (MPC) of "link" type. The length of this latter part is equal to the width of the load blocs (20 $\mathrm{mm}$, figure 2a, $L_{b}$, figure 9). The "link" constraint has been judged as the most appropriate for this case since it allows for a pinned rigid link between the nodes connected while keeping the distance between them constant. Boundary conditions of “pinned” and “encastre” type were applied to points G and H respectively.

The surface JNOK represents the adhesive layer. The upper and lower surfaces of the adhesive are tied together with the respective surfaces of the substrates. The crack inside the adhesive layer is simulated by assigning a "seam crack" to the appropriate line of nodes in the middle of the adhesive layer (figure 9). To calculate the fracture toughness, the J-contour integral method is used. For the needs of this method a contour has been designed circumscribing the crack tip, the form of which is shown in figure 9. The 
substrates were modeled with quadratic triangular elements and a finer mesh was used in the areas of stress concentration. The adhesive was modeled with linear triangular elements. In order to mesh the contour domain linear quadrilateral elements were used, except for the first ring of elements around the crack tip (the smallest of the circles circumscribing the crack tip, figure 9) where linear triangular elements were used. However, these latter elements are translated by Abaqus $^{\mathrm{TM}}$ to linear quadrilateral elements having one side collapsed to a single node (the side corresponding to the crack tip). The validity of this meshing technique for the adhesive has been verified by applying the same principle to a simulation of an infinite plate with a side crack submitted to tensile loading, where the numerical approximation and the theoretical value for the fracture toughness where found to be identical.

The adhesive is modeled as a linear elastic and isotropic material having a Young Modulus of 2.12 GPa and a Poisson ratio of 0.36 . These two values have been provided by the supplier of the adhesive. Since no significant plasticity of the substrates has been observed at the end of the MMB tests for the whole range of the mode mixities that have been examined, it has been decided to model the substrates as linear elastic and isotropic material having as properties the ones given in table 1 for the Raex 450 . In order to calculate $G_{C}$, the distances BD and DF are adjusted according to the values for the lever arm $c$ and the half span length $L$ respectively, which are given in table 4 for each mode mixity tested. All simulations have been performed under load control and under the assumption of a plane strain state. Non-linear geometric effects have also been taken into account. The approximation of the experimental curve has been made at the peak force value. This value was applied to the node A of the model (figure 9). Then, by 
increasing the crack length the best approximation of the corresponding displacement value has been sought (always at point A). The $G_{C}$ value calculated at this point will be the fracture toughness for the specific test. Since the mode mixity $G_{I I} / G_{C}$ decreases as the crack propagates during the experiment, the value of the mode mixity will be recalibrated to fit to the new increased crack length by using the equations (4). The results of the simulations are given in table 4 . An example of the deformed state of the model at the end of the simulation of the experiment MMB20-1 is shown in figure 10. All calculations have been performed using Abaqus ${ }^{\mathrm{TM}} /$ Standard, in parallel mode with 8 cpus, with each simulation time not being longer than 20 minutes.

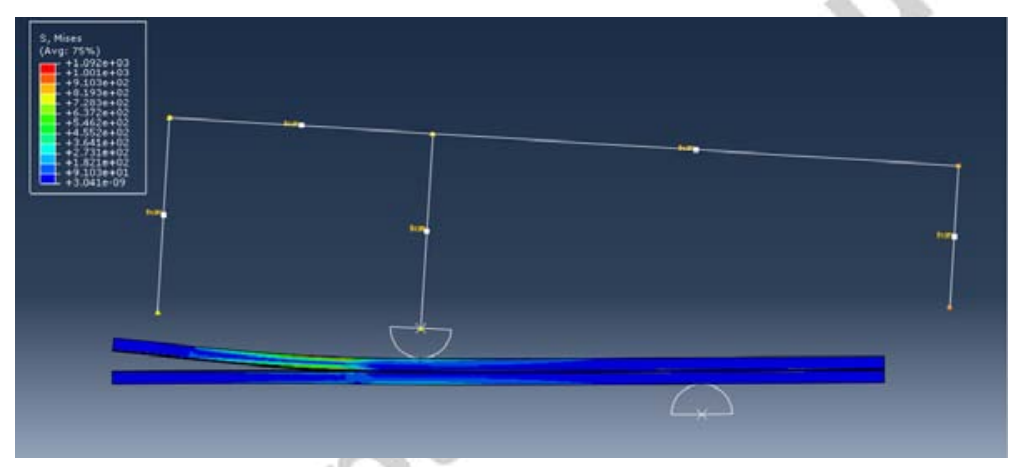

(a)

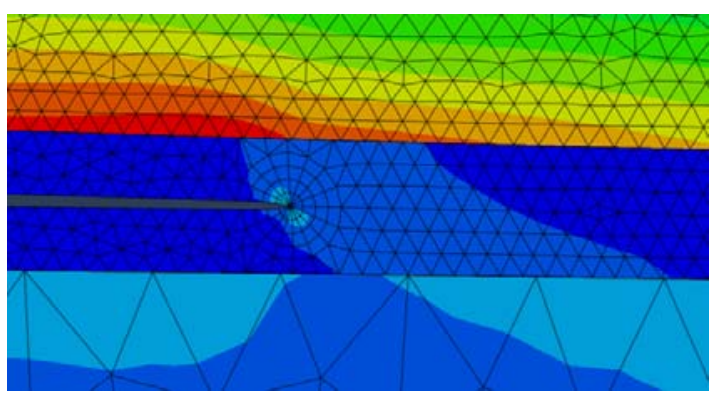

(b)

Figure 10: Example of the deformed state of the finite element model of the MMB test corresponding to the experiment MMB20-1 a) general view, b) detail at the crack tip 


\begin{tabular}{|c|c|c|c|c|c|c|c|c|c|c|c|}
\hline & \multicolumn{2}{|c|}{$\begin{array}{l}\text { Experimental } \\
\text { point to } \\
\text { approximate }\end{array}$} & \multicolumn{2}{|c|}{$\begin{array}{c}\text { Numerical } \\
\text { approximation }\end{array}$} & \multirow{2}{*}{$\begin{array}{c}\text { G } \\
(\mathbf{N} / \mathbf{m} \\
\mathbf{m})\end{array}$} & \multirow{2}{*}{$\begin{array}{l}\text { Statist } \\
\text { ics } \\
\left(G_{C}\right)\end{array}$} & \multirow{2}{*}{$\begin{array}{c}\text { Re- } \\
\text { calibra } \\
\text { ted } \\
\text { G }_{\text {II }} / \mathrm{G}\end{array}$} & \multirow{2}{*}{$\begin{array}{r}\mathrm{G}_{\mathrm{I}} \\
(\mathrm{N} / \mathrm{m} \\
\mathrm{m})\end{array}$} & \multirow{2}{*}{$\begin{array}{c}\text { Statist } \\
\text { ics } \\
\left(G_{I}\right)\end{array}$} & \multirow{2}{*}{$\begin{array}{l}\mathrm{G}_{\mathrm{II}} \\
(\mathrm{N} / \mathrm{m} \\
\mathrm{m})\end{array}$} & \multirow{2}{*}{$\begin{array}{l}\text { Statist } \\
\text { ics } \\
\left(G_{I I}\right)\end{array}$} \\
\hline & $\begin{array}{c}\text { Displace } \\
\text { ment } \\
\text { (mm) }\end{array}$ & $\begin{array}{c}\text { Forc } \\
\text { e } \\
\text { (N) }\end{array}$ & $\begin{array}{l}\text { Displace } \\
\text { ment } \\
\text { (mm) }\end{array}$ & $\begin{array}{c}\text { Forc } \\
\text { e } \\
\text { (N) }\end{array}$ & & & & & & & \\
\hline $\begin{array}{c}\text { MMB } \\
\text { 20-1 }\end{array}$ & 8.23 & $\begin{array}{c}487 . \\
8\end{array}$ & 8.23 & $\begin{array}{c}488 . \\
0\end{array}$ & 3.75 & \multirow{3}{*}{$\begin{array}{c}3.89 \pm \\
0.31\end{array}$} & 0.19 & 3.04 & \multirow{3}{*}{$3.15 \pm$} & 0.71 & \multirow{3}{*}{$\begin{array}{c}0.74 \pm \\
0.06\end{array}$} \\
\hline $\begin{array}{c}\text { MMB } \\
20-2\end{array}$ & 8.76 & $\begin{array}{c}498 . \\
8\end{array}$ & 8.77 & $\begin{array}{c}499 . \\
0\end{array}$ & 3.88 & & 0.19 & 3.14 & & 0.74 & \\
\hline $\begin{array}{c}\text { MMB } \\
20-3\end{array}$ & 8.26 & $\begin{array}{c}502 . \\
0\end{array}$ & 8.24 & $\begin{array}{c}502 . \\
0\end{array}$ & 4.05 & & 0.19 & 3.28 & & 0.77 & \\
\hline $\begin{array}{c}\text { MMB } \\
\text { 40-1 }\end{array}$ & 7.81 & $\begin{array}{c}1015 \\
.0\end{array}$ & 7.83 & $\begin{array}{c}1015 \\
.0\end{array}$ & 5.35 & \multirow{3}{*}{$\begin{array}{l}5.34 \pm \\
0.41\end{array}$} & 0.38 & 3.32 & \multirow{3}{*}{$\begin{array}{c}3.33 \pm \\
0.31\end{array}$} & 2.03 & \multirow{3}{*}{$\begin{array}{c}2.01 \pm \\
0.11\end{array}$} \\
\hline $\begin{array}{c}\text { MMB } \\
40-2\end{array}$ & 7.04 & $\begin{array}{c}1041 \\
.0\end{array}$ & 7.04 & $\begin{array}{c}1041 \\
.0\end{array}$ & 5.13 & & 0.38 & 3.18 & & 1.95 & \\
\hline $\begin{array}{c}\text { MMB } \\
40-3\end{array}$ & 7.21 & $\begin{array}{c}1055 \\
.0\end{array}$ & 7.23 & $\begin{array}{c}1056 \\
.0\end{array}$ & 5.54 & & 0.37 & 3.49 & & 2.05 & \\
\hline $\begin{array}{c}\text { MMB } \\
60-1\end{array}$ & 7.55 & $\begin{array}{c}1632 \\
.0\end{array}$ & 7.56 & $\begin{array}{c}1632 \\
.0\end{array}$ & 7.59 & \multirow{3}{*}{$\begin{array}{l}7.14 \pm \\
0.79\end{array}$} & 0.59 & 3.11 & \multirow{3}{*}{$\begin{array}{c}2.95 \pm \\
0.28\end{array}$} & 4.48 & \multirow{3}{*}{$\begin{array}{c}4.19 \pm \\
0.52\end{array}$} \\
\hline $\begin{array}{c}\text { MMB } \\
60-2\end{array}$ & 7.28 & $\begin{array}{c}1564 \\
.0\end{array}$ & 7.25 & $\begin{array}{c}1564 \\
.0\end{array}$ & 6.86 & & 0.58 & 2.88 & & 3.98 & \\
\hline $\begin{array}{l}\text { MMB } \\
60-3\end{array}$ & 7.00 & $\begin{array}{c}1596 \\
.0\end{array}$ & 7.00 & $\begin{array}{c}1596 \\
.0\end{array}$ & 6.97 & & 0.59 & 2.86 & & 4.11 & \\
\hline $\begin{array}{c}\text { MMB } \\
\text { 80-1 }\end{array}$ & 7.20 & $\begin{array}{c}2008 \\
.0\end{array}$ & 7.26 & $\begin{array}{c}2008 \\
.0\end{array}$ & 8.06 & \multirow{3}{*}{$\begin{array}{c}9.05 \pm \\
1.72\end{array}$} & 0.80 & 1.61 & \multirow{3}{*}{$\begin{array}{c}1.81 \pm \\
0.35\end{array}$} & 6.45 & \multirow{3}{*}{$\begin{array}{l}7.24 \pm \\
1.38\end{array}$} \\
\hline $\begin{array}{c}\text { MMB } \\
\text { 80-2 }\end{array}$ & 8.21 & $\begin{array}{c}2122 \\
.0\end{array}$ & 8.21 & $\begin{array}{c}2122 \\
.0\end{array}$ & 9.50 & & 0.80 & 1.90 & & 7.60 & \\
\hline $\begin{array}{c}\text { MMB } \\
\text { 80-3 }\end{array}$ & 8.04 & $\begin{array}{c}2150 \\
.0\end{array}$ & 8.00 & $\begin{array}{c}2150 \\
.0\end{array}$ & 9.60 & & 0.80 & 1.92 & & 7.68 & \\
\hline
\end{tabular}

Table 4: Simulation results of the MMB tests for the fracture toughness $G_{C}$ (the statistics concern the mean value \pm 2 times the standard deviation). 


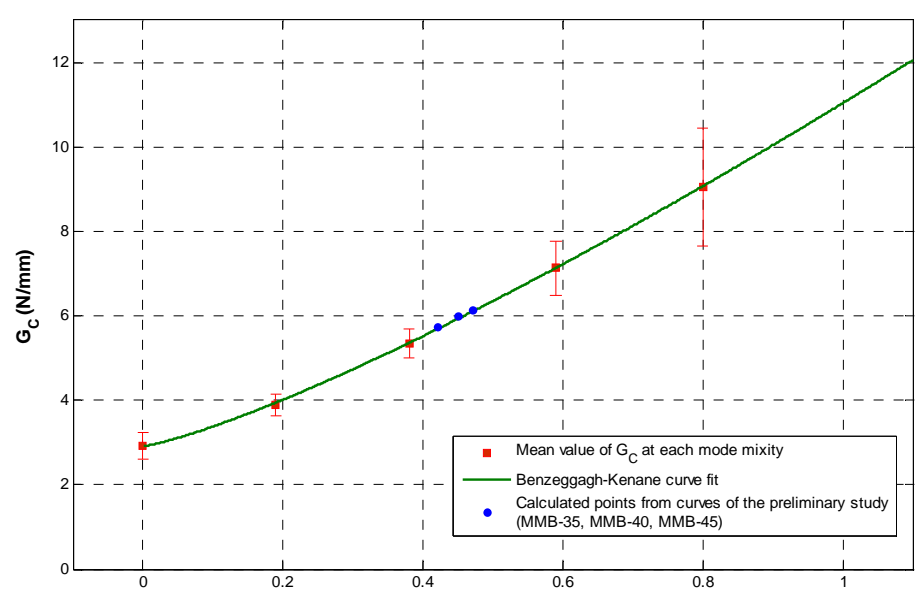

(da)

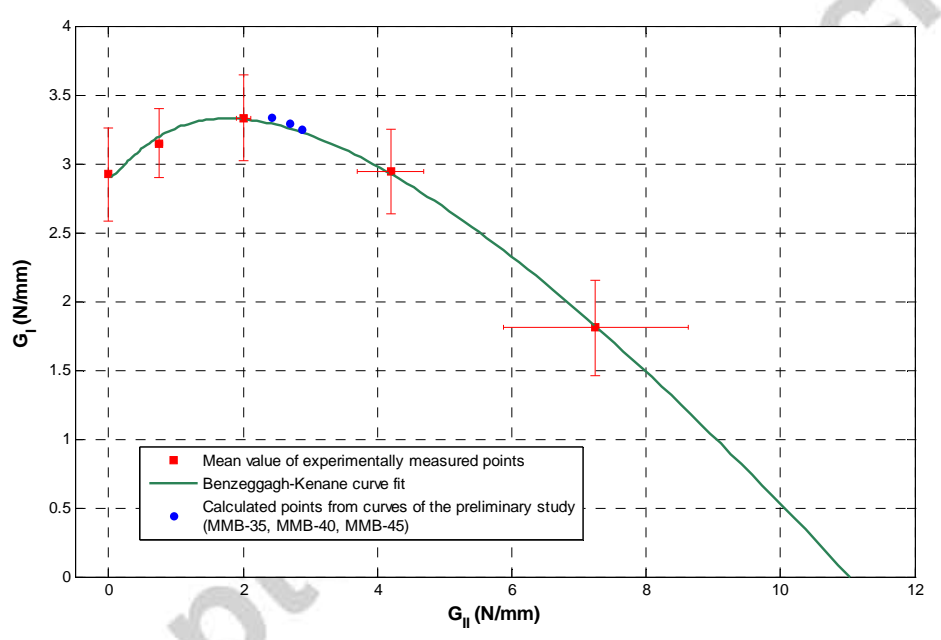

(b)

Figure 11: a) Evolution of the fracture toughness $G_{C}$ as a function of the mode mixity $G_{I I} / G_{C}$, b) Evolution of the fracture toughness $G_{I}$ as a function of the fracture toughness $G_{I I}$ 


\subsection{Combining TDCB - MMB results and discussion}

The results from the TDCB and MMB experiments enable the full fracture envelope of the SikaPower ${ }^{\circledR}-498$ adhesive to be studied. Figure 11a shows the evolution of the fracture toughness $G_{C}$ as a function of the mode mixity $G_{I I} / G_{C}$. Figure 11 b shows the evolution of $G_{I}$ as a function of $G_{I I}$. In both graphs, the mean value \pm 2 times the standard deviation is plotted. It is convenient in the graph shown in figure $11 \mathrm{~b}$ to plot also the horizontal error bar, which represents the error in the calculation of $G_{I I}$. The experimental results of the fracture toughness obtained from the first $3 \mathrm{MMB}$ preliminary tests (figure 7), where the initial crack length was at 35, 40 and $45 \mathrm{~mm}$, have also been added. The other experimental curves of the MMB preliminary study were not examined any further.

As a first observation when looking at the graphs in figure 11, the considerable increase of the fracture energy with the mode mixity may be noted. In particular, the fracture energy is almost tripled when increasing the mode mixity to 0.8 : $G_{I C}$ is around $3 \mathrm{~N} / \mathrm{mm}$ (table 2) and $G_{C}$ at $G_{I I} / G_{C}=0.8$ is around of $9 \mathrm{~N} / \mathrm{mm}$ (table 4). This large increase in the fracture toughness value when moving from the mode I load case to the mode II load case is logical and has been observed in many other previous studies (as for example in Marzi et al. [25]). In addition, the increasing variation of the fracture resistance results with the mode mixity can also be noted. In addition, it must also be noted that the error in the measurement of the fracture toughness $G_{C}$ increases with the mode mixity (figure 11a), and in particular the error in the measurement of $G_{I I}$ (figure 11b). Indeed, when 
looking at table 4, it can be seen that the error in the measurement of $G_{I I}$ increases from $\pm 0.06 \mathrm{~N} / \mathrm{mm}$ (at $G_{I I} / G_{C}=0.2$ ) to $\pm 1.38 \mathrm{~N} / \mathrm{mm}$ (at $G_{I I} / G_{C}=0.8$ ). On the contrary, the error in measuring $\mathrm{G}_{\mathrm{I}}$ is of the order of $\pm 0.30 \mathrm{~N} / \mathrm{mm}$ and does not change significantly when increasing the mode mixity (see also tables 2 and 4).

Of particular interest is the tendency observed in the graphs shown in figure 11. If we focus on the graph in figure $11 \mathrm{~b}$, it can be seen that $G_{I}$ increases from about $3 \mathrm{~N} / \mathrm{mm}$ (pure mode I load case) to a plateau value of the order of $3.3 \mathrm{~N} / \mathrm{mm}$ (which corresponds to $G_{I I} / G_{C}=0.4$ ), and then starts to decrease almost linearly to zero (the pure mode II load case). According to the power law criterion, when plotting $G_{I}$ as a function of $G_{I I}$, $G_{I}$ should remain almost constant up to a certain mode mixity value before starting to decrease to zero [18]. In our case, it can be clearly seen that this behavior is inadequate to fully describe the evolution of $G_{I}$ as a function of $G_{I I}$. However, the tendency observed for the SikaPower ${ }^{\circledR}-498$ seems to be adequately described by the BenzeggaghKenane [30] failure criterion, which in 2D may be expressed as

$$
G_{C}=G_{I C}+\left(G_{I I C}-G_{I C}\right)\left(\frac{G_{I I}}{G_{C}}\right)^{m}
$$

where $m$ is a material parameter to be defined. Normally, if $G_{I I C}$ and $G_{I C}$ are measured experimentally only $m$ needs to be specified. This is usually done by a least squares fit of the experimental results taking as value of $m$ the one which minimizes the error between the experimental data and the predicted data. In the present case, since $G_{I I C}$ has not been measured experimentally, it was estimated when performing the least squares fit. This has been done by defining equation (6) in Matlab ${ }^{\mathrm{TM}}$ as a custom equation entering two constants to be estimated when fitting the experimental data: $m$ and $G_{I I C}$. The independent variable was the mode mixity $G_{I I} / G_{C}$ and $G_{I C}$ has been set constant at 
$2.93 \mathrm{~N} / \mathrm{mm}$ (the mean value, table 3). With this procedure, $m$ has been calculated at 1.24 and $G_{\text {IIC }}$ at $11.03 \mathrm{~N} / \mathrm{mm}$. Thus, the Benzeggagh-Kenane failure criterion for the SikaPower ${ }^{\circledR}-498$ (green curve, figure 11) takes the form

$$
G=2.93+8.10\left(\frac{G_{I I}}{G_{C}}\right)^{1.24}
$$

At this point, it is convenient to make a comparison between the results for the fracture toughness $G_{I C}$ and $G_{I I C}$ obtained in our study for a layer width of the SikaPower ${ }^{\circledR}-498$ adhesive at $0.5 \mathrm{~mm}$, with the corresponding ones from the work of Marzi et al. [25]. The mean value of $G_{I C}$ in the present study was measured to be $2.93 \mathrm{~N} / \mathrm{mm}$ (table 3 ) and the mean value of $G_{I I C}$ was estimated at $11.03 \mathrm{~N} / \mathrm{mm}$. The corresponding values given from the Marzi et al [25] study are: $\mathrm{G}_{\mathrm{IC}}=4.23 \mathrm{~N} / \mathrm{mm}$ (for an adhesive layer width of $0.58 \mathrm{~mm}$ evaluated with the Irwin-Kies equation) and $G_{I I C}=13.3 \mathrm{~N} / \mathrm{mm}$ (for an adhesive layer width of $0.36 \mathrm{~mm}$ evaluated with the ENF test). At a first glance, it can be seen that the values of $G_{I C}$ and $G_{I I C}$ in both cases are of the same order of magnitude. However, both $G_{I C}$ and $G_{I I C}$ given in our study are a little lower than the ones obtained by Marzi et al. [25]. The reasons for this could be attributed to the differences in the adhesive layer thickness. However, there are also other differences between the two studies, such as the type of tests used, the standards applied, the curing cycle of the adhesive and the TDCB substrate materials.

\section{Conclusions}

In this study, the fracture behavior of a modern crash optimized single-component epoxy adhesive SikaPower ${ }^{\circledR}-498$ has been measured under pure mode I and mixed mode I/II load cases. The TDCB test according to the ISO standard [6] has been used to 
calculate the $G_{I C}$ fracture toughness and five specimens were examined. The mixed mode I/II fracture behavior has been evaluated using the MMB apparatus developed by Reeder and Crews [27]. Mode partitioning has been performed using the methodology described in the ASTM standard [26]. Four values of the mode mixity $G_{I I} / G_{C}$ have been examined (0.2, 0.4, 0.6 and 0.8$)$ and 3 tests per mode mixity have been performed. A finite element model in Abaqus $^{\mathrm{TM}}$ has been developed to calculate the fracture toughness $G_{C}$ at each mode mixity tested. The results from the previous 2 methodologies have enabled the fracture envelope of the SikaPower ${ }^{\circledR}-498$ adhesive to be constructed. It has been shown that the fracture envelope can be adequately described by the Benzeggagh-Kenane [30] empirical criterion expressed in 2D. The values for the $G_{I C}$ and $G_{I I C}$ fracture toughness $(2.93 \mathrm{~N} / \mathrm{mm}$ and $11.03 \mathrm{~N} / \mathrm{mm}$ respectively) are a little lower than the ones measured previously for the same adhesive by Marzi et al [25] (4.23 $\mathrm{N} / \mathrm{mm}$ and $13.3 \mathrm{~N} / \mathrm{mm}$ respectively). This discrepancy was mainly attributed to the differences in the adhesive layer thickness used in the two studies.

Several perspectives may be envisaged for the next step of this study. During the evaluation of the experimental results only the LEFM principles have been used. The non-linear behavior of the adhesive has not been taken into account. Even though the values measured for the fracture toughness appear coherent, a future study should integrate the non-linear behavior of the adhesive in the analysis of the experimental results and compare with the results issued when applying the LEFM principles. In addition, it would be interesting to compare the fracture behavior issued in this study for the SikaPower ${ }^{\circledR}-498$ adhesive with that obtained using different measurement techniques. Finally, it would also be useful to quantify the influence of the adhesive 
thickness and the loading rate on the fracture behavior under mixed mode loading. Several of these points are currently being investigated. 


\section{References}

1. Ripling EJ, Mostovoy S, Patrick RL, Measuring fracture toughness of adhesive joints. Materials Research and Standards, ASTM, Vol.64, No.3, 1964, p.129134.

2. Mostovoy S, Crosley PB, Ripling EJ, Use of crack-line loaded specimens for measuring plane-strain fracture toughness. J Mater, 2(3) (1967) 661-681.

3. ASTM D3433, in Annual Book of ASTM standards, Adhesives section 15. Philadelphia, PA: ASTM; 1990.

4. Blackman B.R.K., Kinloch A.J., Paraschi M., Teo W.S., Measuring the mode I adhesive fracture energy, $\mathrm{G}_{\mathrm{IC}}$, of structural adhesive joints: the results of an international round-robin, Int J Adhes Adhes 23 (2003) 293-305.

5. Blackman, B.R.K., Hadavinia, H., Kinloch, A.J., Paraschi, M. and Williams, J.G., The calculation of adhesive fracture energies in mode I: revisiting the tapered double cantilever beam (TDCB) test, Eng Fract Mech, 70(2) (2003) 233248.

6. Adhesives - Determination of the Mode I Adhesive Fracture Energy $\mathrm{G}_{\mathrm{IC}}$ of Structural Adhesive Joints Using Double Cantilever Beam and Tapered Double Cantilever Beam Specimens. ISO (2009) 25217.

7. Kanninen MF, Popelar CH. Advanced fracture mechanics. Oxford: Oxford University Press; 1985. 
8. K.S. Alfredsson, On the instantaneous energy release rate of the end-notch flexure adhesive joint specimen, Int J Solids Struct, 41 (2004) 4787-4807. \{8\}

9. K. Leffler, K.S. Alfredsson, U. Stigh, Shear behaviour of adhesive layers, Int J Solids Struct, 44 (2007) 530-545.

10. Blackman, B.R.K., Kinloch, A.J., Paraschi, M., The determination of the mode II adhesive fracture resistance, $\mathrm{G}_{\mathrm{IIC}}$, of structural adhesive joints: An effective crack length approach, Eng Fract Mech, 72 (2005) 877-897.

11. Martin R.H., Davidson B.D., Mode II fracture toughness evaluation using four point bend, end notched flexure test, Plast Rubber Compos 28(8) (1999) 401406(6).

12. Lucas F.M. da Silva, David A. Dillard, Ramber R.K. Blackman, Robert D. Adams, Testing Adhesive Joints, Wiley-VCH, 2012.

13. Chai H., Shear fracture, Int J Fracture, 37 (1988) 137-159.

14. T. Andersson, U. Stigh, The stress-elongation relation for an adhesive layer loaded in peel using equilibrium of energetic forces, Int J Solids Struct, 41(2004) 413-434.

15. V. Tamuzs, S. Tarasovs, U. Vilks, Delamination properties of translaminarreinforced composites, Compos Sci Technol, 63 (2003) 1423-1431.

16. Stigh U, Damage and crack growth analysis of the double cantilever beam specimen. Int J Fracture 37 (1988) R13-R18.

17. Rice J.R., A path Independent Integral and the Approximate Analysis of Strain Concentration by Notches and Cracks, J Appl Mech, 35 (1968) 379-386. 
18. Whitcomb J. D., Analysis of instability-related growth of a through-width delamination. NASA TM-86301, 1984.

19. Goyal V. K., Johnson E. R., Goyal V. K., Predictive strength-fracture model for composite bonded joints, Compos Struct 82 (2008) 434-446.

20. Gustafson P. A., Waas A. M., The influence of adhesive constitutive parameters in cohesive zone finite element models of adhesively bonded joints, Int J Solids Struct, 46 (2009) 2201-2215.

21. Biel A., Stigh U., Damage and plasticity of adhesive layers: an experimental study, Procedia Engineering 10 (2011) 2280-2285.

22. Yang Q.D., Thouless, M.D., Ward, S.M., Mixed-mode fracture analyses of plastically-deforming adhesive joints. Int J Fracture, 110 (2001) 175-187.

23. Kafkalidis M.S., Thouless M.D., The effects of geometry and material properties on the fracture of single lap-shear joints, Int J Solids Struct, 39 (2002) 43674383.

24. Salomonsson K., Mixed mode modeling of a thin adhesive layer using a mesomechanical model, Mech Mater, 40 (2008) 665-672.

25. Marzi S., Anders B., Ulf Stigh, On experimental methods to investigate the effect of layer thickness on the fracture behavior of adhesively bonded joints, Int J Adhes Adhes (2011), doi:10.1016/j.ijadhadh.2011.08.004.

26. Standard test method for Mixed Mode I - Mode II interlaminar fracture toughness of unidirectional fiber-reinforced polymer-matrix composites. ASTM D6671/ D6671M (2006).

27. Crews, J.H. Jr. and Reeder, J.R. A Mixed Mode Bending Apparatus for Delamination Testing, 1988, NASA-TM-100662. 
28. Ducept F., Davies P., Gamby D., Mixed mode failure criteria for a glass/epoxy composite and an adhesively bonded composite/composite joint, Int J Adhes Adhes, 20 (2000) 233-244.

29. Determination of the mode I adhesive fracture energy, $\mathrm{G}_{\mathrm{IC}}$, of structural adhesives using the double cantilever beam (DCB) and tapered double cantilever beam (TDCB) specimens. BS 7991:2001 (2001).

30. M. L. Benzeggagh \& M. Kenane, Measurement of mixed mode delamination fracture toughness of unidirectional glass/epoxy composites with mixed-mode bending apparatus, Compos Sci Technol, 56 (1996) 439-449. 